\title{
A 14-Week Intervention Study on Changing Preservice Teachers' Psychological Perspectives on Inclusion: Explicit and Implicit Attitudes, Self-Efficacy, and Stress Perception Toward Inclusion
}

\author{
Franziska Lautenbach ${ }^{1 *}$, Johanna Korte ${ }^{1}$, Aiko Möhwald $^{1}$, Anke Heyder $^{2}$ and \\ Elke Grimminger-Seidensticker ${ }^{1}$
}

${ }^{1}$ Department of Sport and Sport Science, TU Dortmund University, Dortmund, Germany, ${ }^{2}$ Department of Psychology, TU Dortmund University, Dortmund, Germany

OPEN ACCESS

Edited by:

Bernhard Ertl,

Universität der Bundeswehr

München, Germany

Reviewed by:

Sabine Glock,

University of Wuppertal, Germany

Cevdet Cengiz,

Çanakkale Onsekiz Mart University,

Turkey

*Correspondence:

Franziska Lautenbach

Franziska.Lautenbach@uni-leipzig.de

Specialty section:

This article was submitted to

Educational Psychology,

a section of the journal

Frontiers in Education

Received: 12 June 2019 Accepted: 21 January 2020

Published: 28 February 2020

Citation:

Lautenbach F, Korte J,

Möhwald A, Heyder A and Grimminger-Seidensticker E (2020) A

14-Week Intervention Study on Changing Preservice Teachers'

Psychological Perspectives on Inclusion: Explicit and Implicit Attitudes, Self-Efficacy, and Stress

Perception Toward Inclusion. Front. Educ. 5:7.

doi: 10.3389/feduc.2020.00007
Research has indicated the importance of preservice teacher education programs that focus on fostering positive psychological aspects relevant to teaching in inclusive settings, such as attitudes or self-efficacy. Previous research lacks theoretical underpinning and is limited because of methodological characteristics of the studies (e.g., no control group). Thus, in a quasi-experimental design the current study aimed to investigate the effects of theoretically derived interventions (IG1: information-based cognitive intervention group; IG2: information-based and practical field experience intervention group) in comparison to a control group (CG) on changes in preservice teachers' perspective on teaching inclusively, i.e. explicit and implicit attitudes, selfefficacy, and stress perception, all relevant to teach in inclusive settings. Results of four separated repeated-measure analysis of variances, with time of assessment (before vs. after) as a within-subject factor and group (CG, IG1, and IG2) as a between-subject factor, showed no differences in the development (pre- to post-intervention) between CG and IG1 as well as CG and IG2 in any of the dependent variables. However, significant differences in changes in explicit attitudes and stress perception were found between IG1 and IG2 in favor of IG2. Results will be discussed considering confounding variables that future research should further investigate.

Keywords: Physical Education, teacher training, university intervention, inclusion, attitude

\section{INTRODUCTION}

Over the last two decades, the changing psychological perspectives held by (preservice) teachers that are relevant to inclusive teaching in teacher training programs have gained a respectable amount of research interest (see reviews by Kurniawati et al., 2014; Lautenbach and Heyder, 2019). This is not surprising, given political decisions such as the Convention on the Rights of Persons with Disabilities (United Nations, 2006), which requires regular schools to include students with special needs and (preservice) teachers to teach inclusively. Teaching inclusively is generally "associated with providing services to ensure that all students regardless of their ability can achieve their full 
potential in an appropriate education setting" (O'Brien et al., 2009 , p. 46). On the other hand, such an inclusive education system and teaching inclusively require particular skills, behavior, and attitudes (Darling-Hammond and Bransford, 2007; Krischler and Pit-ten Cate, 2019), as well as particular structural conditions (Booth and Ainscow, 2011). This means, for example, that teachers are required to plan their lessons with the abilities of all students in mind, that they support the learning and participation of all students with a variety of pedagogical arrangements, and that they make use of students' differences as a resource for teaching and learning (Booth and Ainscow, 2011). Teachers (and preservice teachers) need to be open-minded and evaluate inclusion as an opportunity, and not as a threat (Pajares, 1992). However, empirical evidence has shown that (preservice) teachers perceive inclusive settings as stressful and do not feel properly prepared to teach inclusively (e.g., Boujut et al., 2016). Thus, preservice teacher education plays a crucial role (e.g., ArthurKelly et al., 2013). A focus on preservice teacher education is especially relevant in this early career phase, as the psychological aspects addressed are more perceptible to change (e.g., Hutzler et al., 2005). Further, not only is the evaluation of the effectiveness of preservice teacher education programs continually needed (Coates and Vickerman, 2008)-previous research on improving (preservice) teachers' attitudes toward inclusion lacks theoretical underpinning and is limited as a result of methodological issues.

\section{Theoretical Considerations for Changing Psychological Perspectives on Inclusion in Preservice Teacher Education}

In this study, we focus on preservice teachers' attitudes, selfefficacy, and stress-perception. In what follows, we define each construct, elaborate on why it matters for inclusive education, and how it could be addressed in preservice teacher education.

\section{Implicit and Explicit Attitudes}

Following the theory of planned behavior (Ajzen, 1991), attitudes are broadly defined as "beliefs people hold about the object" (Ajzen, 1991, p. 191). They are linked via behavioral intentions to behavior. Thus, it could be argued that attitudes toward inclusion are theoretically linked to teaching behavior that has been shown in empirical studies (e.g., Yeo et al., 2014). Therefore, more positive attitudes are considered to be the most influential factor for implementing successful inclusion (Avramidis and Norwich, 2002). For instance, teachers' attitudes toward including students with special educational needs in mainstream classes were found to be related to students' social integration in inclusive classes (Heyder et al., 2020). However, the sensitivity of the topic of inclusion can lead to socially desirable answers when only relying on questionnaire data in order to assess teachers' attitudes (Lautenbach and Antoniewicz, 2018). Therefore, measures of implicit attitudes should be integrated into educational research as well (Glock and Kovacs, 2013).

In detail, based on the associative-propositional evaluation (APE) model (Gawronski and Bodenhausen, 2006), two qualitatively distinct but interacting processes form attitudes: the associative process and the propositional process. Based on an individual's immediate affective reaction toward a stimulus (i.e. associative process), for example, the concept of inclusive education, implicit attitudes are formed. The propositional process validates (i.e. confirms or disconfirms) this evoked gut feeling based on internally logical information (i.e. propositional process). In other words, the evoked emotional reaction "will be regarded as valid unless it is inconsistent with other information" (Gawronski and Bodenhausen, 2006, p. 66). Based on the APE model, a change in attitudes can be accomplished by either directly influencing propositional processes (i.e. explicit attitudes), by providing new information, or associative processes (i.e. implicit attitudes), by forming new positive associations-for example, by paring the attitudes object with positive (or negative) stimuli (Gawronski and Bodenhausen, 2006). By applying the APE model to preservice teacher education programs with the goal of improving attitudes toward inclusion, an intervention could target propositional (i.e. cognitive) or associative (i.e. affective) processes or processes (i.e. cognitive and affective; see Lautenbach and Heyder, 2019).

\section{Self-Efficacy and Stress}

Furthermore, self-efficacy that is the "perceived judgments of how well one can execute courses of action required to deal with prospective situation" (Bandura, 1982, p. 122) and stress that is "an organized psychophysiological reaction to ongoing relationships with the environment" (Lazarus, 2000, p. 230) are related to attitudes. Hutzler et al. (2005) proposed a theoretical model of teachers' reaction to having to include a child with special needs. The model states that self-efficacy directly affects the stress perception and, thereby, affects teachers' attitudes toward inclusion (Hutzler et al., 2005, p. 13). In other words, the higher (preservice) teachers' self-efficacy, the less the situation is perceived as stressful and the more positive their explicit attitudes toward teaching inclusively are. Empirically, and in line with Hutzler's model, the subjectively perceived stress when imagining having to teach inclusively has previously been shown to predict up to a $33 \%$ unique variance of explicit attitudes toward inclusion (Lautenbach, 2019). Also, a recent study with French preservice teachers showed that attitudes toward inclusion is related positively to self-efficacy (Desombre et al., 2018).

Finally, there is evidence that (preservice) teachers perceive inclusive settings as stressful and that (preservice) teachers do not feel prepared properly for teaching inclusively (e.g., Boujut et al., 2016). Thus, enhancing self-efficacy might be a key factor for successfully teaching in inclusive settings. Self-efficacy can be increased by four sources according to Bandura, 1977, p. 195): performance accomplishments (e.g., performance exposure, performance desensitization), vicarious experience (e.g., live modeling), verbal persuasion (e.g., suggestion, self-instruction), and emotional arousal (e.g., symbolic desensitization, coping skills). On a theoretical level, several sources can be tackled during an intervention to increase self-efficacy and can be related to the transactional model of stress and coping by Lazarus (2000). Within this model, a stress reaction is based on the subjective evaluation of the relevance of a stressor and the individual's perceived resources-one can argue as part of self-efficacyto deal with this stressor. Therefore, increasing self-efficacy by 
increasing perceived resources should reduce stress (according to Lazarus, 2000).

\section{Combined Theoretical Approach on Changing Psychological Aspects Toward Inclusion in Preservice Teachers}

Information-based cognitive interventions (i.e. seminars in the classroom) provide potentially new information and thus primarily tackle propositional processes to change attitudes. In addition, this form of intervention might increase sources of self-efficacy such as verbal persuasion and potentially vicarious experience (e.g., role-playing and attitudinal empathy-building; see Shade and Stewart, 2001). As self-efficacy can be considered part of the evaluation process (i.e. appraisal) of an individual's perceived resources (i.e. self-concept of own competencies and control expectancy; see Gaab, 2009), an increase in self-efficacy should lead to a decrease in stress (see also model by Hutzler et al., 2005, p. 13). Overall, this would justify assuming that information-based cognitive interventions should lead to an increase in positive attitudes and self-efficacy and to a decrease in stress perception.

However, practical field experiences in combination with sufficient and adequate theoretical preparation and reflection (see Reflective Practitioner by Schön, 2017) also provide the opportunity to tackle associative processes, in addition to experiencing more sources of self-efficacy (see also Desombre et al., 2018). We could therefore argue that a combination of information and practical field experience, compared with a purely information-based intervention,

(1) provides more chances to increase attitudes, mainly because of the possibility to form new (and positive) associative processes that could also impact propositional processes (Gawronski and Bodenhausen, 2006);

(2) offers quantitatively and qualitatively more valuable sources to increase self-efficacy (i.e. personal accomplishments; Bandura, 1977); and

(3) provides the possibility to implement and practice coping skills, thereby reducing stress perception.

\section{Empirical Evidence on Changing Psychological Perspectives on Inclusion in Preservice Teacher Education}

At first glance, there is empirical evidence that explicit attitudes toward inclusion assessed via questionnaires can successfully be increased in preservice teachers providing informationbased as well as information-based in combination with field experience-based interventions (see review of 23 studies by Lautenbach and Heyder, 2019). For example, a Canadian study on 72 preservice teachers found that after a course of either eight consecutive days of providing information on inclusion $(n=36)$ or by concurrently participating in a class over 12 weeks $(n=36)$, a significant increase in attitudes toward inclusion was present in both groups (Killoran et al., 2014). Studies focusing on a combination of information-based and field experience-based interventions also report significant increases in explicit attitudes, for example, after one semester (McHatton and Parker, 2013). On the contrary, however, the only study that compared an information-based cognitive intervention with a combination of information-based and field experience intervention in 55 undergraduate Elementary Education majors found neither a significant difference in attitudes between the intervention groups because of the intervention nor a significant difference within each group from before and after (Yellin et al., 2003). Despite the seemingly positive impact of university interventions on attitudes toward inclusion, almost all of the recently reviewed intervention studies have methodological (i.e. lack of control groups, except for one study by Gürsel, 2007) and statistical shortcomings (i.e. multi-comparison of only single items). Thus, actual conclusions can hardly be drawn regarding the effectiveness of interventions that aim to increase attitudes toward inclusion in preservice teachers (Lautenbach and Heyder, 2019, p. 18).

Only a few studies have aimed to change psychological aspects other than explicit attitudes that are assumed to be relevant in preservice teacher education. Several studies have included a measurement of concern toward inclusion, but did not find significant changes for example in 67 preservice teachers after 13 weeks of introduction to inclusion classes and additional "social experience with people with disabilities" $(n=17)$ or a "selected non-contact option" ( $n=50$; Forlin and Chambers, 2011, p. 21). There is, to our knowledge, only one study that implemented implicit and explicit attitude measures as well as self-efficacy measures (Scanlon and Barnes-Holmes, 2013). Attitudes did not change after four 2-hour lectures over the course of 4 weeks on behavioral intentions, plus a 1-day workshop on stress management interventions. Regarding self-efficacy, results showed only a significant increase for teachers $(n=25)$, but not for teachers in training $(n=20$; Scanlon and BarnesHolmes, 2013). With respect to preservice teachers, again, to our knowledge, there is only one intervention study (one semester; "Introduction to Inclusion class") focusing on preservice teachers and their changes in explicit attitudes toward inclusion as well as self-efficacy (Tournaki and Samuels, 2016). Significant changes in self-efficacy were found in neither 98 general nor 76 special education majors.

Overall, little is known about the effects of university classes on self-efficacy and implicit attitudes, and nothing so far is known about stress perception. Additionally, studies that aimed to increase attitudes toward inclusion and/or selfefficacy via university classes almost never implemented a control group (except Gürsel, 2007), and only one study compared two types of intervention, finding no significant changes in explicit attitudes (Yellin et al., 2003). Therefore, it still remains unclear how effective university interventions actually are and which type of intervention-an informationbased intervention or a combining intervention with cognitive information and field experience-might be the most successful one in changing relevant psychological aspects in regard to inclusion (Lautenbach and Heyder, 2019, p. 18).

\section{The Present Study}

Overall, studies focusing on the explicit attitudes of (preservice) teachers toward inclusion have shown "predominantly negative 
or undecided beliefs and feelings toward inclusive education" (De Boer et al., 2011, p. 348) as well as slightly positive or ambivalent attitudes (see review by Reuker et al., 2016, p. 92). These findings raise the question of what constitutes "positive attitudes toward inclusion" (see for a discussion, see also Lautenbach and Heyder, 2019, p. 18).

Studies have suggested that, for example, scores above 4 on a Likert scale from 1 to 6 (e.g., Schwab and Seifert, 2015) are an indication of positive attitudes. However, the attitudes depend on the type of disability and vary tremendously (i.e. for mental disability, $70.2 \%$ show "neutral" attitudes and $23.7 \%$ "positive" attitudes; for physical disability, 28.6\% show "neutral" attitudes and $71.4 \%$ "positive" attitudes). With respect to implicit attitudes, studies have found "neutral" implicit attitudes (Lüke and Grosche, 2017, p. 7) and "ambivalent" implicit attitudes toward inclusion (Lautenbach and Antoniewicz, 2018, p. 28). Thus, from a theoretical (i.e. the theory of planned behavior; APE model) as well as from an empirical perspective, we would argue that fostering positive attitudes in preservice teachers is still of relevance for teacher education training programs.

Finally, as preservice teachers perceive inclusive settings as stressful and do not feel properly prepared for teaching inclusively (e.g., Boujut et al., 2016)-even though it is part of the educational reform in Europe to prepare them (see e.g., Meijer, 2011) — we aimed to implement an intervention study to increase attitudes and self-efficacy as well as to decrease stress perception in preservice teachers.

Thereby, the main focus of this study is on the question of what type of intervention (i.e. information-based cognitive vs. a combination of information-based cognitive and field experience intervention; based on Lautenbach and Heyder, 2019) has a stronger impact on psychological parameters with respect to inclusive teaching in comparison to a control condition.

We implemented a quasi-experimental intervention study (i.e. main difference between experiments is no random assignment of participants to intervention or control group; see Shadish et al., 2001, p. 14) with three university study groups. The first group underwent an information-based cognitive intervention (intervention group 1; IG1), the second group followed a combination of information-based cognitive and field experience intervention (intervention group 2; IG2), and the third group functioned as a control group (CG). Since a random assignment of students to the intervention groups and control group was not feasible for ethical as well as practical reasons (e.g., students had other courses that might take place at the same time), a quasi-experimental design was the method of choice. The focus of this study was on Physical Education (PE) preservice teachers. In $\mathrm{PE}$, in comparison to other subjects in school, students learn holistically (i.e. cognitively, affectively, motorically, and socially; Sherrill, 2004), and PE differs in organizational aspects (e.g., the students are not seated, the space is extended in a gym, injuries are possible). Thus, physical disability is supposed to play a greater role for PE preservice teachers (see Leineweber et al., 2015). Dependent variables were preservice teachers' explicit and implicit attitudes toward inclusion, their self-efficacy, and their stress perception with respect to teaching in inclusive settings.
We first hypothesized that both forms of interventions (i.e. IG1 and IG2) will lead to a significant increase in implicit and explicit attitudes, self-efficacy, and a significant decrease in stress perception toward inclusion in comparison to the control group (i.e. CG; hypothesis 1). Second, we hypothesized that a combination of cognitive information and practical field experience will lead to a higher increase in attitudes and selfefficacy and a higher decrease in stress perception in comparison to providing an only information-based cognitive intervention (IG2 > IG1; hypothesis 2).

\section{MATERIALS AND METHODS}

\section{Participants}

A total of 73 preservice teachers majoring in Physical Education (PE) and one other subject participated in one of three seminars, i.e. two intervention groups and one control group. The seminars were mandatory for all students during their Bachelor's program and thus, no additional recruitment process took place. Also, no additional classes with respect to the topic (i.e. inclusion in Physical Education) were held by the same lecturer (i.e. first author), and thus, no further participants could have been implemented in the study. Students decided on a seminar time and were thereby allocated to one of the three groups. However, only complete data sets of 62 participants (85\%) were obtained because of students' absence during pre- $(n=7)$, post-testing $(n=3)$, or unwillingness to participate $(n=1)$. All preservice $\mathrm{PE}$ teachers voluntarily participated in this quasi-experimental mixed-design study.

The control group (CG; $n=20 ; 9$ females) consisted of 5 special and 15 regular Physical Education majors. The second subject of the 15 regular education majors was either Chemistry $(n=2)$, German $(n=1)$, German and Mathematics $(n=4)$, English $(n=3)$, Mathematics $(n=2)$, Philosophy $(n=1)$, Pedagogy $(n=1)$, or not reported $(n=1)$. The participants were on average 23.6 years old $(S D=3.72)$ and were in their fourth semester $(M=4.30 ; S D=2.32)$. 11 students stated that they had previous theoretical experience at university with the topic of inclusion. Furthermore, 11 students stated that they had previous practical experience with inclusion.

The intervention group 1 (i.e. information-based cognitive intervention, IG1; $n=23 ; 10$ females) consisted of 6 special and 17 regular Physical Education majors. The second subject of the 17 regular education majors was either chemistry $(n=1)$, German $(n=1)$, German and Mathematics $(n=4)$, English $(n=1)$, Mathematics $(n=4)$, Physics $(n=1)$, Pedagogy $(n=1)$, Social Science $(n=1)$, Economics $(n=2)$, or not reported $(n=1)$. The participants were on average 23.7 years old $(S D=3.34)$ and were in their sixth semester $(M=5.69 ; S D=2.29)$. 11 students stated that they had previous theoretical experience at university with the topic of inclusion. 10 students stated that they had previous practical experience with inclusion.

The intervention group 2 (i.e. a combination of informationbased cognitive and practical field experience intervention; IG2; $n=19 ; 12$ females) consisted of 7 special and 12 regular Physical Education majors. The second subject of the 12 regular 
education majors was either Chemistry $(n=1)$, German $(n=3)$, German and Mathematics $(n=4)$, Mathematics $(n=2)$, Pedagogy $(n=1)$, or not reported $(n=1)$. The participants were on average 22.1 years old $(S D=1.66)$ and were in their fourth semester $(M=4.37 ; S D=0.96) .7$ students stated that they had previous theoretical experience at university with the topic of inclusion. 12 students stated that they had previous practical experience with inclusion.

\section{Measures and Material Demographic Questionnaire}

Participants were asked to report age, gender, years at university (i.e. semesters studied), and their study subject (i.e. major and second subject). Additionally, participants were asked whether they have had practical experience with inclusion in their private life (i.e. knowing someone with disability), during their time in school (e.g., being taught inclusively or observing inclusive education during their school internships), or outside of school (e.g., being in a sports club with someone; i.e. yes vs. no). In addition, before and after the intervention, they were asked to report whether they have had any academic experience with the topic of inclusion during their studies at university, such as seminars or lectures (yes vs. no). If they answered yes, they were additionally asked for the detailed amount in semester periods (unit: $45 \mathrm{~min}=1$ semester period). All control variables are relevant, as they have been shown to be related to attitudes toward inclusion in preservice teachers (see, e.g., reviews by De Boer et al., 2011; Qi and Ha, 2012; Reuker et al., 2016).

\section{Explicit Attitudes}

The validated German version of the Questionnaire on Attitudes Toward Inclusion for Teachers (Seifried and Heyl, 2016) was used to assess explicit attitudes. Participants were asked to answer 15 questions on a 5-point Likert scale ranging from 1 (strongly disagree) to 5 (strongly agree) with an overall reliability of $\alpha=0.87$. The questionnaire consists of three subscales, assessing, teachers' "willingness to teach inclusively" (five items; example item: "I can imagine teaching an inclusive class next term"; $\alpha=0.84$ ), attitudes toward "promoting academic competencies" in inclusive settings (six items; example item: "Children with special needs will be equally supported in both a regular class and in a special needs class"; $\alpha=0.80$ ), and the possibility of students with special needs for "social inclusion" (four items; example item: "Children with special needs will be treated well by other children in an inclusive class"; $\alpha=0.85$ ). This questionnaire is especially relevant when focusing on explicit attitudes toward inclusion, as it provides information relevant for preservice teachers' perception of teacher-related components, as well as on student-related components (see Seifried and Heyl, 2016).

\section{Implicit Attitudes}

The Single-Target Implicit Association Test (ST-IAT) with prerated words was used to measure implicit attitudes and has recently been used specifically in the context of measuring implicit attitudes toward inclusion in preservice education teachers (Lautenbach and Antoniewicz, 2018). The ST-IAT is a computerized classification task assessing reaction times to target concepts (i.e. "inclusion"; items: together, heterogeneity, variety, participation, integration, special needs, handicap, equality) and two evaluative categories (i.e. "pleasant" vs. "unpleasant"). Thereby, it measures the strength of associations, assuming that strongly associated concepts (e.g., "inclusion" + "pleasant") lead to faster and more accurate responses (for further detail, please see Lautenbach and Antoniewicz, 2018). The split-half test reliability coefficient has been found to be between 0.72 ("inclusion" and "pleasant") and 0.81 ("inclusion" and "unpleasant") and is considered satisfactory (Lautenbach and Antoniewicz, 2018, p. 27). In the end, a D-Score was calculated, and a higher $D$-score represents a more positive implicit attitude.

\section{Teachers' Self-Efficacy}

Self-efficacy was assessed using the validated Perceived Teacher Self-Efficacy questionnaire as it was theoretically developed with Bandura's concept of self-efficacy in mind (Schwarzer and Hallum, 2008). Participants responded to 10 questions, such as "I am convinced that I am able to teach successfully all relevant subject content to even the most difficult students," on a 4-point Likert scale ranging from 1 (disagree) to 4 (agree). While reliability within the current sample was questionable ( $\alpha=0.57)$, previous studies showed good reliability $(\alpha=0.81$; Schwarzer and Hallum, 2008).

\section{Stress Perception}

The level of subjectively perceived stress when imagining teaching PE inclusively was measured using the validated Primary Appraisal Secondary Appraisal Scale (PASA; Gaab, 2009) as it was theoretically developed based on the transactional theory of stress by Lazarus (2000). Participants were asked to answer 16 questions on the specific situation of imagining having to teach an inclusive class as a PE teacher (following Boujut et al., 2016), using a 6point Likert scale ranging from 1 (totally incorrect) to 6 (totally correct). The PASA consists of four situation-specific subscales assessing challenge (four items; example item: "The situation is important for me"; $\alpha=0.36$ ) and threat (four items; example item: "I do not feel threatened by the situation"; $\alpha=0.82)$, which form the primary appraisal subscale $(\alpha=0.610)$, in addition to self-concept of own competencies (four items; example item: "I know what I have to do in this situation"; $\alpha=0.88$ ) and control expectancy (four items; example item: "I can control a lot myself of what I can do in this situation"; $\alpha=0.57$ ), which form the secondary appraisal subscale $(\alpha=0.661)$. Next, a stress index that served as the indicator of teachers' stress perception in the following analyses was derived by subtracting the secondary appraisal from the primary appraisal mean scores (see Gaab, 2009). A higher stress index indicates a higher subjective level of stress.

\section{Seminar/Intervention Content}

All seminars generally aimed to provide an overview of different theoretical models and different perspectives relevant for teaching PE. The classes were structured into 14 units at $90 \mathrm{~min}$ and were taught by the same lecturer (i.e. first author). In general, the used models, theories, and empirical data within 
this class were based on German literature to ensure a fit to the future-working environment of the preservice teachers (see Supplementary Appendix A for detailed intervention content). Information provided to the students was generally processed by the students themselves in a student-centered teaching approach via constellation work, group discussions, role-play, group work, or specific homework. A summary of the provided information and discussion context was, however, generally given by the lecturer at least at the end of each session in a teacher-centered teaching approach (see Supplementary Appendix A for detailed instructional actives in accordance with Wanzek et al., 2016).

Identical classes were taught in 8 out of the 14 sessions (i.e. sessions $1,2,4,5,6,8,10$, and 11). However, whereas the CG discussions were always related to a general school setting, in the IGs these discussions, discussions on how to practically apply the content to a school setting (e.g., session 6: group processes in $\mathrm{PE}$ ) were always related to inclusive education settings. In comparison to IG1, which, for example, discussed the topic of inclusion and the necessity of empathy to relate to pupils, IG2 also discussed those competencies included in CG discussions, but additionally participated in a rehabilitation and disabled sports community for pupils for $4 \mathrm{~h}$. In detail, the sports program in rehabilitation and the disabled sports community was taught by experienced instructors. The students' role was defined as actively participating, and they were asked to engage with the pupils on sight. They had no further responsibilities. They were given the possibility to choose from 13 different sports such as beat bees, a dancing class for children with autism, a sport for people with intellectual disabilities, or a wheelchair sports for kids. The deliberate choice preservice teachers were given was realized not only because individuals preferably decide on their own (e.g., Perfecto et al., 2017), but also because making one's own decision fosters motivation because of an increased sense of autonomy (see self-determination theory by Ryan and Deci, 2000).

\section{Cover Story}

Participants were not fully informed about the aim of the study, to reduce socially desirable answers. Preservice teachers were told that several questionnaires and computer tasks would need to be performed for quality management. Participants were fully debriefed after the post measurement.

\section{Evaluation of the Seminar Quality and Seminar Attendance}

A self-constructed questionnaire, provided by the Department for Higher Education Development, was used for the evaluation of the seminar quality. Students were asked to answer 28 items focusing on the seminar concept and structure, the lecturer, the requirements for the seminar, the learning success, their participation, and finally, an overall judgment on the class, which was used as the focal indicator of students' perceived seminar quality. All items were rated on a 5-point Likert scale, ranging from 1 (successful) to 5 (not successful).

Additionally, preservice teachers' attendance during the semester was monitored. The same procedure was applied for the practical field experience by the supervisor of the field course (i.e. head of rehabilitation and disabled sports community Dortmund 51 e.V.).

\section{Procedure}

The study protocol was approved by the Ethics Committee of TU Dortmund University (approval number: 2017 3) and conducted in accordance with the Declaration of Helsinki. A random assignment of participants to the experimental groups was not feasible because of ethical as well as practical reasons. Instead, participants decided for one course based on the seminar time. In order to maximize the strength of the quasi-experimental design, we tested for a priori differences between the groups in important demographic characteristics and target variables. Data on explicit and implicit attitudes, as well as on self-efficacy and stress perception, were collected during the first and last seminar sessions. Pre-and post-testing followed the same structure because of organizational reasons: First, participants were instructed about the experiment (i.e. cover story) and were asked to sign the informed consent form. Second, participants were asked to fill out all questionnaires (i.e. demographic questionnaire, explicit attitudes, self-efficacy, stress perception) and were then asked to go to the laboratory in groups of four in order to perform a computer-based categorization task (i.e. ST-IAT).

In the laboratory, they were welcomed by an experimenter and asked to sit in front of a computer. In order to minimize disruption, participants were all seated facing a wall and given earplugs. Participants were then asked to follow the procedure of the ST-IAT.

\section{Data Analyses}

All variables were checked for normal distribution and outliers (mean $\pm 3 S D$ ).

First, we tested for distribution differences between the groups in regard to gender, their study subject (i.e. general vs. special education), and their academic or practical experience with inclusion (i.e. yes vs. no) using chi-square tests. Also, we tested differences between the groups with respect to age and semesters in university, as well as for all dependent variables (i.e. explicit attitude total score, explicit attitudes subscales, implicit attitude, self-efficacy total score, stress index), running univariate analyses of variance (ANOVAs). Post hoc tests with a Bonferroni-adjusted alpha-level were used to follow up on occurring main effects (Field, 2013, p. 69).

Furthermore, in order to control for university classes in which students participated during the semester and that may have also focused on the topic of inclusion, mean differences from pre- to post-testing on the number of classes on inclusion were calculated, and a univariate analysis of variance (ANOVA) was conducted. Post hoc tests with a Bonferroni-adjusted alpha level were used to follow up on occurring main effects.

For the purpose of comparing differences in perceived quality of teaching between the three groups (CG, IG1, and IG2), we also ran a univariate ANOVA using preservice teachers' overall judgment of the seminars. For the purpose of controlling for attendance in the seminar, we ran an additional univariate ANOVA entering the number of times preservice teachers were 
present in the seminar. Post hoc tests with a Bonferroni-adjusted alpha level were used to follow up on occurring main effects.

Finally, for hypotheses testing, we conducted four separated repeated-measure ANOVAs with time of assessment (before vs. after) as a within-subject factor, group as a between-subject factor (CG, IG1, IG2), and either explicit attitude (i.e. attitude total score), implicit attitude (i.e. D-Score), self-efficacy (i.e. total score), or stress index as a dependent variable. For all analyses, the level of significance was initially set at $p<0.05$. Bonferroni-adjusted alpha-level post hoc analyses were used to identify any potential main effects. For significant interaction effects, independent $t$-tests with an adjusted significance level of $\leq 0.025$ were performed, thereby comparing the mean changes in dependent variables from pre to post between CG to IG1 and IG2 (Hypothesis 1), as well as IG1 to IG2 (Hypothesis 2).

\section{RESULTS}

\section{Differences Between Groups}

Prior to the intervention, the groups did not differ in regard to age, $F(2,59)=1.672, p=0.197, \eta_{p}^{2}=0.054$; gender distribution, $\chi^{2}(2, N=62)=1.907, p=0.385, \phi=0.175$; the distribution of the study subject, $\chi^{2}(2, N=62)=0.817, p=0.665, \phi=0.115$; or their practical experience with inclusion, $\chi^{2}(2, N=62)=1.656$, $p=0.437, \phi=0.163$, and the amount of academic experience they had with the topic of inclusion in university, $F(2,58)=0.069$, $p=0.933, \eta_{p}{ }^{2}=0.002$. A significant difference was found in the students' semesters in university, $F(2,59)=3.398$, $p=0.040, \eta_{p}{ }^{2}=0.103$. However, post hoc Bonferroni corrected analyses presented no significant differences between CG and IG1 (mean difference $=-1.40 ; p=0.076, d=0.61$ ), CG and IG2 (mean difference $=-0.07 ; p>0.999, d=0.04$ ), as well as IG1 and IG2 (mean difference $=1.33 ; p=0.106$, $d=0.76)$.

Prior to the intervention, the groups also did not differ with respect to explicit attitudes toward inclusion in total, $F(2,59)=1.462, p=0.240, \eta_{\mathrm{p}}{ }^{2}=0.047$, as well as on all subscales, i.e. "willingness to teach inclusively," $F(2,59)=0.653$, $p=0.524, \eta_{\mathrm{p}}{ }^{2}=0.021$; "promoting academic competencies," $F(2,59)=1.642, p=0.202, \eta_{\mathrm{p}}{ }^{2}=0.053$; and "social inclusion," $F(2,59)=1.065, p=0.351, \eta_{\mathrm{p}}{ }^{2}=0.035$. No differences prior to intervention were found for implicit attitudes toward inclusion, $F(2,59)=1.158, p=0.321, \eta_{\mathrm{p}}^{2}=0.038$; their self-efficacy, $F(2,59)=0.565, p=0.571, \eta_{\mathrm{p}}{ }^{2}=0.019$; and finally, their stress index, $F(2,59)=0.978, p=0.382, \eta_{p}^{2}=0.032$. For descriptive statistics on the dependent variables please see Tables 1, 2.

Post intervention, a significant difference in the semester periods on the topic of inclusion during the semester was detected, $F(2,58)=5.702, p=0.005, \eta_{\mathrm{p}}{ }^{2}=0.118$ with a power of 0.99. Post hoc analyses showed that CG has overall joined a similar number of seminar sessions on topics of inclusion during the semester as IG1 $\left(M_{C G}=15.1, S D_{C G}=30.5 ; M_{I G 1}=10.63\right.$, $\left.S D_{I G 1}=27.65, d=0.62\right)$. However, IG2 $\left(M_{I G 2}=37.36\right.$, $\left.S D_{I G 2}=20.57\right)$ had a significantly higher number of sessions on the topic of inclusion during the semester than IG1 $(p=0.007$, $d=1.11)$ and CG $(p=0.035, d=0.87)$.

\section{Seminar Quality}

Preservice teachers rated all seminars excellent with respect to the quality of teaching $\left(M_{C G}=1.04, S D_{C G}=0.20 ; M_{I G 1}=1.18\right.$, $\left.S D_{I G 1}=0.40 ; M_{I G 2}=1.05, S D_{I G 2}=0.22\right)$. No significant differences between the groups were found, $F(2,63)=1.663$, $p=0.198, \eta_{\mathrm{p}}^{2}=0.025$.

\section{Seminar Attendance}

Preservice teachers' attendance did not significantly differ between the groups, $F(2,59)=0.469, p=0.628 \eta_{\mathrm{p}}^{2}=0.008$. The average seminar classes missed for the groups are: $M_{C G}=2.00$, $S D_{C G}=0.86 ; M_{I G 1}=2.30, S D_{I G 1}=1.33$, and $M_{I G 2}=2.42$, $S D_{I G 2}=1.89$.

\section{Attitudes Changes Related to the Intervention \\ Explicit Attitudes}

The repeated-measure ANOVA revealed no main effect, $F(1.59)=0.157, p=0.639, \eta_{\mathrm{p}}{ }^{2}=0.003$ with a power of 0.107 , for explicit attitudes. However, as expected, a significant interaction effect between attitudes change and group, $F(2,59)=3.958$, $p=0.024, \eta_{\mathrm{p}}{ }^{2}=0.118$ with a power of 0.99 , was detected. Following up on this interaction, an independent $t$-test showed no significant difference in the attitudes changes from before and after between CG and IG1 $(p=0.103, d=0.52)$, as well as between CG and IG2 ( $p=0.389, d=0.29)$, not supporting Hypothesis 1. However, a significant difference between IG1 and IG2 was observed, $t(40)=3.418, p=0.001$, $d=0.87$ with a power of 0.78 . As presented in Figure 1, the change in attitudes was higher in IG2 than in IG1. Please see Tables 1, 2 for descriptive data on attitudes pre and post intervention for each group.

To gain more insights into which aspect of the explicit attitudes has indeed changed, we decided to first run additional exploratory univariate analyses using mean differences from before and after each subscale (i.e. "social inclusion," "promoting academic competencies," "willingness to teach inclusively"), following up with a Bonferroni-adjusted post hoc analyses.

The change from before and after post did not differ between the groups for the subscale of "social inclusion" $(p=0.441$, $\left.\eta_{\mathrm{p}}{ }^{2}=0.027\right)$. However, significant differences were found for the "willingness to teach inclusively," $F(2,59)=3.401, p=0.040$, $\eta_{\mathrm{p}}{ }^{2}=0.103$ with a power of 0.11 , and the subscale "promoting academic competencies," $F(2,59)=3.187, p=0.048, \eta_{\mathrm{p}}{ }^{2}=0.098$ with a power of 0.11. Post hoc Bonferroni tests revealed no significant differences in the changes between CG and IG1 ("willingness to teach inclusively": $p=0.868, d=0.34$; "promoting academic competencies": $p=0.226, d=0.06$ ) and IG2 ("willingness to teach inclusively": $p=0.417, d=0.43$; "promoting academic competencies": $p>0.999, d=0.19$ ). However, a significant difference in changes between IG1 and IG2 was observed with respect to the "willingness to teach inclusively" ( $p=0.035, d=0.9$ ) and a tendency for the "promotion of academic competencies" ( $p=0.06, d=0.95)$. Please see Figure 1. 
TABLE 1 | Descriptive data on explicit and implicit attitudes toward inclusion for each group before (pre) and after (post) intervention.

\begin{tabular}{|c|c|c|c|c|c|c|c|c|c|c|c|c|}
\hline & \multicolumn{6}{|c|}{ Explicit attitude (mean score) } & \multicolumn{6}{|c|}{ Implicit attitude (D-score) } \\
\hline & \multicolumn{2}{|c|}{$\mathbf{C G}$} & \multicolumn{2}{|c|}{ IG1 } & \multicolumn{2}{|c|}{ IG2 } & \multicolumn{2}{|c|}{ CG } & \multicolumn{2}{|c|}{ IG1 } & \multicolumn{2}{|c|}{ IG2 } \\
\hline & Pre & Post & Pre & Post & Pre & Post & Pre & Post & Pre & Post & Pre & Post \\
\hline $\mathrm{M}$ & 3.68 & 3.75 & 4.05 & 3.80 & 3.94 & 4.2 & 0.01 & 0.12 & 0.13 & 0.27 & 0.20 & 0.15 \\
\hline SD & 0.72 & 0.92 & 0.65 & 0.78 & 0.81 & 0.62 & 0.32 & 0.38 & 0.35 & 0.34 & 0.49 & 0.25 \\
\hline Min.--max. & $2.80-5.20$ & $2.33-5.73$ & $2.47-5.07$ & $2.13-5.40$ & $1.93-5.33$ & $3.27-5.13$ & $-0.55-0.67$ & $-0.63-0.84$ & $-0.51-0.77$ & $-0.27-0.89$ & $-0.72-1.26$ & $-0.37-0.72$ \\
\hline
\end{tabular}

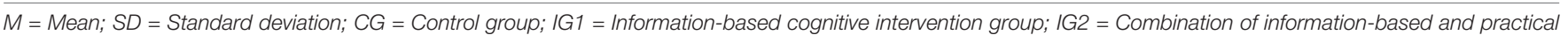
field experience intervention.

TABLE 2 | Descriptive data on self-efficacy and stress index when imagining how to teach inclusive PE for each group before (pre) and after (post) intervention.

\begin{tabular}{|c|c|c|c|c|c|c|c|c|c|c|c|c|}
\hline & \multicolumn{6}{|c|}{ Self-efficacy (total sum score) } & \multicolumn{6}{|c|}{ Stress index } \\
\hline & \multicolumn{2}{|c|}{ CG } & \multicolumn{2}{|c|}{ IG1 } & \multicolumn{2}{|c|}{ IG2 } & \multicolumn{2}{|c|}{ CG } & \multicolumn{2}{|c|}{ IG1 } & \multicolumn{2}{|c|}{ IG2 } \\
\hline & Pre & Post & Pre & Post & Pre & Post & Pre & Post & Pre & Post & Pre & Post \\
\hline M & 30.1 & 29.8 & 37 & 35 & 36 & 36 & 0.02 & -0.18 & -0.43 & -0.23 & -0.17 & -0.73 \\
\hline $\mathrm{SD}$ & 2.71 & 3.46 & 2.83 & 3.01 & 2.9716 & 2.36816 & 0.87 & 1.21 & 1.20 & 1.142 & 1.04 & 0.74 \\
\hline Min.-max. & $23-34$ & $25-38$ & $26-37$ & $25-35$ & $27-36$ & $28-36$ & $-1.63-1.38$ & $-2.88-2.00$ & $-2.75-1.75$ & $-1.88-2.38$ & $-1.63-1.75$ & $-2.00-0.88$ \\
\hline
\end{tabular}

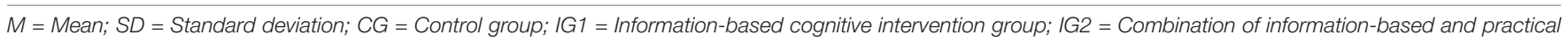
field experience intervention.

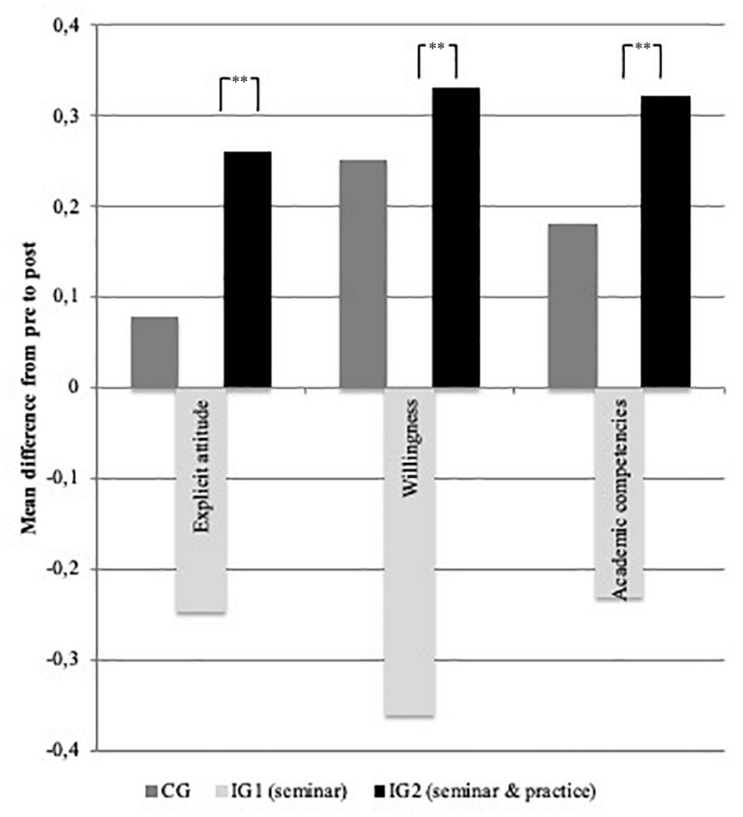

FIGURE 1 | Mean difference from pre to post for overall explicit attitude and for the subscales "willingness to teach inclusively" as well as "promoting academic competencies"; ${ }^{\star *} p<0.01$.

\section{Implicit Attitude}

For implicit attitude the repeated-measure ANOVA showed no significant main, $F(1.59)=1.313, p=0.256, \eta_{\mathrm{p}}{ }^{2}=0.022$ with a power of 0.529 , or interaction effect, $F(2,59)=0.946$, $p=0.394, \eta_{\mathrm{p}}{ }^{2}=0.031$ with a power of 0.690 . Please see Tables 1, 2 for descriptive data on implicit attitude pre and post intervention for each group.

\section{Self-Efficacy and Stress Perception Changes Related to the Intervention}

For self-efficacy, neither significant changes over time, $F(1.59)=0.415, p=0.522, \eta_{\mathrm{p}}^{2}=0.007$ with a power of 0.194 , nor significant changes over time with respect to group, $F(2,59)=0.036, p=0.965, \eta_{\mathrm{p}}{ }^{2}=0.001$ with a power of 0.068 , were found. Please see Tables 1, 2 for descriptive data on self-efficacy and stress pre and post intervention for each group.

For stress perception, the repeated-measure ANOVA showed no significant main effect, $F(1.59)=2.815, p=0.099, \eta_{\mathrm{p}}{ }^{2}=0.046$ with a power of 0.864 . However, a significant interaction effect was found, $F(2,59)=3.946, p=0.025, \eta_{\mathrm{p}}{ }^{2}=0.118$ with a power of 0.99 . Following up on this interaction, independent $t$-tests showed no significant difference in the changes from before and after in stress perception between CG and IG1 $(p=0.118$, $d=0.50)$ as well as between CG and IG2 $(p=0.220, d=0.41)$, not supporting Hypothesis 1. However, a significant difference between IG1 and IG2 was observed, $t(40)=2.693, p=0.010$, $d=0.85$ with a power of 0.76 , in the direction that the decrease in stress was higher in IG2.

To closely identify which aspects of the stress perception had indeed changed, we decided to run additional exploratory univariate analyses using mean differences from before and after for each subscale (i.e. "challenge," "threat," "self-concept of own competencies," and "control expectancy"), following up the with Bonferroni post hoc analyses for occurring main effects. 
A significant difference between the changes in the groups was found for the subscales "threat," $F(2,59)=4.638, p=0.013$, $\eta_{\mathrm{p}}{ }^{2}=0.136$, and "self-concept of own competencies", $F(2,59)=4.191, p=0.02, \eta_{\mathrm{p}}{ }^{2}=0.124$, but not for "challenge" $\left(p=0.643, \eta_{\mathrm{p}}{ }^{2}=0.015\right)$ and "control expectancy" ( $p=0.975$, $\left.\eta_{\mathrm{p}}{ }^{2}<0.001\right)$. Bonferroni post hoc analyses revealed that the change in the threat perception of teaching inclusively differed significantly between CG and IG1 $(p=0.029, d=0.87)$, presenting a decrease in CG $(M=-0.14, S D=1.03)$ and an increase in IG1 $(M=0.35, S D=0.71)$. No difference between CG and IG2 was found ( $p>0.999, d=0.03$ ). However, a significant difference in the change in threat perception between IG1 and IG2 was observed ( $p=0.043, d=1.06$ ), showing a decrease in IG2 $(M=-0.38, S D=1.05)$. With respect to the self-concept of own competencies, Bonferroni post hoc analyses presented no difference between CG and IG1 $(p>0.999, d=0.13)$. No significant differences were found between changes in IG2 $(M=0.55, S D=1.17)$ in comparison to CG $(M=-0.63$, $S D=0.62 ; p=0.072, d=0.68)$. However, a significant difference in changes was observed between IG1 $(M=-0.14, S D=0.63)$ and IG $2(p=0.027, d=0.78)$ with respect to self-concept of own competencies. Please see Figure 2.

\section{DISCUSSION}

The importance of university classes and curricula in increasing psychological aspects in preservice teachers with respect to inclusion has been recognized to be of high importance (ArthurKelly et al., 2013). Thus, the aim of this field study was to investigate the effects of two theoretically derived interventions on PE preservice teachers' attitudes (i.e. explicit and implicit), self-efficacy, and stress perception. We did this by implementing an advanced quasi-experimental study design (i.e. implementing

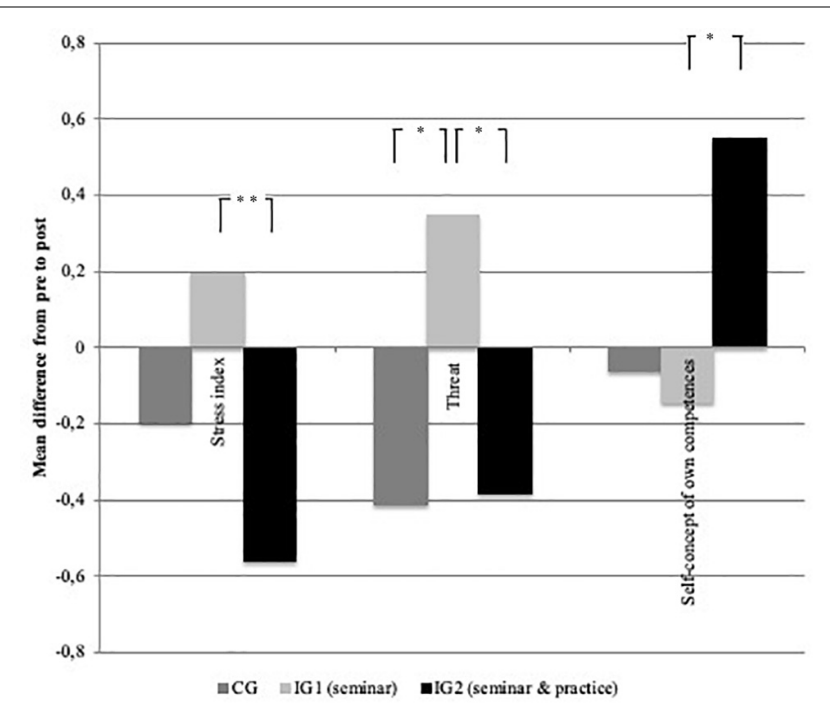

FIGURE 2 | Mean difference from pre to post for overall stress index and the subscales "threat as well as self-concept of own competencies"; " $p<0.05$, $* * p<0.011$. a control group; all seminars taught by the same lecturer). Surprisingly, results did not show that the interventions had a significant effect in comparison to the control condition on all dependent variables. Therefore, the investigation of the second research question (i.e. which type of intervention leads to a more positive effect on the psychological constructs under investigation) might appear obsolete at first glance. However, we consider the results regarding the second research question beneficial for future research. In detail, we found an increase in explicit attitudes and a decrease in stress perception to be more pronounced in IG2 (i.e. a combination of informationbased cognitive and practical field experience) than in IG1 (i.e. information-based cognitive intervention), which partially supports our second hypothesis. Nevertheless, we are aware that none of the interventions led to significant changes in the psychological constructs compared to the control condition, and results should be interpreted with caution.

To our knowledge, this is the first field study that investigated two forms of interventions and additionally implemented a control group with the goal of positively affecting psychological constructs regarding inclusion in a quasi-experimental beforeand-after design. Therefore, this study could be considered a pilot study that builds the basis for larger studies in the future. The methodological strengths of the present study, however, also make it difficult to compare the current results to previous study results. Thus, we will discuss the current results on content and on methodological issues (e.g., sample size).

\section{No Differences in Changes of Psychological Perspectives With Regard to Inclusion Between CG and IG1 as Well as IG2 (Hypothesis 1)}

That the intervention groups showed no significant differences in the development of the psychological constructs in comparison to the control group is somewhat surprising, as the control group has not been provided information on inclusion during that class. As we controlled for the quality of teaching and non-significant differences were observed, other reasons need to be considered to understand the current results. Additionally, we controlled for attendance, but also analyses showed no significant differences for missed classes between the groups. Further, we can exclude the possibility that the three groups differed in the number of other seminars on the same or similar topics attended by the preservice teachers. The CG has overall joined a similar number of seminar sessions on topics of inclusion as IG1 during the semester, whereas only IG2 reported a number of sessions on the topic of inclusion during that semester significantly higher than IG1 and CG. Nevertheless, it remains unclear why no differences in changes between CG and IG2 were detected.

It could be argued that, on a descriptive level, even though not statistically significant, IG1 and IG2 had more positive attitudes toward inclusion, higher self-efficacy, and lower stress perception in comparison to CG prior to intervention, which might have caused ceiling effects. Thus, although IG2 improved on a descriptive level (for example, in their attitudes after the 
intervention in comparison to CG), there were no statistically significant differences between the changes in CG and IG2.

\section{Differences in Changes of Psychological Perspectives With Regard to Inclusion Between IG1 and IG2 (Hypothesis 2)}

The hypothesized differences in changes in psychological perspectives toward inclusion between IG1 and IG2 were supported with respect to explicit attitudes and stress perception. Contrary to our expectations, we saw no differences between IG1 and IG2 in the changes in implicit attitude and selfefficacy from before and after. Nevertheless, as we were unable to show differences between the intervention groups and the control group (Hypothesis 1), the results should be interpreted with caution and may only be useful for example for future meta-analyses.

\section{Increase in Explicit Attitudes and Decrease in Stress Perception in IG2 in Comparison to IG1}

It is surprising that, on a descriptive level, preservice teachers in IG1 actually showed a decrease in attitudes as well as an increase in stress perception in comparison to IG2. This is not in line with the theoretical assumptions, nor with previous research presenting positive effects on attitudes after an information-based cognitive intervention (e.g., Killoran et al., 2014). One possible explanation might be sensitization: Researchers have argued that only providing information might lead to a sensitization of the topic (e.g., Wegner, 2001). This sensitization could increase awareness to inclusive teaching; but without being given, observing, or discussing in detail proper action alternatives or behavioral strategies on how to handle inclusive settings, the stress perception of inclusive teaching might increase and selfconcept of own competencies might decrease. In accordance with the model by Hutzler et al. (2005), this negatively affects attitudes toward inclusion. The causality of the described process is speculative in nature, however, an increase in threat perception, a drop in self-concept of own competencies, and a decrease in explicit attitudes, particularly in the willingness to teach inclusively, can be seen in the current data of IG1 not only descriptively, but also statistically in comparison to IG2 that showed a decrease in stress perception and an increase in explicit attitudes.

Further, the current results of IG1 and IG2 are not wellaligned with prior research. Another study that also compared the two types of intervention reported only an increase in one attitude subscale in the information-based cognitive intervention group, whereas no changes were detected in the combined intervention group (Yellin et al., 2003). Apart from using different statistical approaches, the authors argued, with respect to the non-significant changes in their combined intervention group, that the time period was not long enough, that the nature of the involvement (primarily observation) was insufficient, or that simple exposure to children with special needs might not be a sufficient condition to change attitudes to teach in inclusive settings (Yellin et al., 2003, p. 16). Based on our current results, we would claim that not the length of the practical field experience (current intervention: 4-6 h within one semester; Yellin et al., 2003: $300 \mathrm{~h}$ ), but rather the nature of the involvement played a crucial role in the contrary findings. In order to impact attitudes positively by contact (see contact theory by Allport, 1954), about 120 conditions for "optimal" contact have been identified (see Pettigrew and Tropp, 2005). However, as quality of contact (e.g., equal status of relationships) plays at least an equally important role as quantity (i.e. amount of contact; in accordance with Pettigrew and Tropp, 2005), we would argue that the quality of contact differed between our field-based experience and that intervention implemented by Yellin et al. (2003). In detail, preservice teachers in our study actually did sports together with students with special needs, therefore, a rather equal status of relationship can be assumed. Depending on the sport (e.g., playing wheelchair basketball), it might even be that preservice teachers were rather in an inferior status, as they have never performed such movements and might have needed support by the students. In contrast, the preservice teachers in the study by Yellin et al. (2003) were in a rather superior position by helping the teachers or on occasion tutoring the students, presenting an unequal status of relationship. Additionally, they mainly observed, and thus, less interaction could be assumed in comparison to the preservice teachers in the current study. Finally, it should be kept in mind that preservice teachers will eventually be in a "superior" status, as they will have to teach students with special needs in regular classrooms. However, our data support the argument by Yellin et al. (2003) that simple exposure to children with special needs might not be enough. In the same vein, we would emphasize the importance of the quality of interaction that should preferably be on an equal status-at least for the first interactions. Thereby, practical field experience under this condition (e.g., doing sports together) could represent a good first step with a low threshold particularly for students in their first semesters to enhance explicit attitudes toward teaching inclusively.

\section{No Differences in Changes in Implicit Attitude and Self-Efficacy Between IG1 and IG2}

Contrary to our expectations, we saw no differences in the changes from before and after between IG1 and IG2 in implicit attitude and self-efficacy. We first focused on implicit attitude. Gawronski and Bodenhausen (2006) argue that implicit attitude can either be externally influenced by directly impacting association activation or indirectly impacted by propositional validation impacting associative processes eventually. For IG1, we would argue that only the indirect impact was addressed; whereas for IG2, both impact forms, that is direct impact on implicit attitude via association activation because of the field experience, as well as indirect impact via information and propositional validation during the seminar, were present. Thus, the indirect impact in IG1 might not have been strong enough to influence implicit attitude, as it was not strong enough to impact explicit attitudes. A reason for no effects on implicit attitude with respect to IG2 could be found in the questionable stability of rapidly learned implicit attitude changes (Glock and Kovacs, 2013, p. 515). However, research has demonstrated that effects on implicit attitude changes can last at least $24 \mathrm{~h}$ (focusing on 
stereotypes; Kawakami et al., 2000) - 17 out of the 19 preservice teachers in IG2 finished their practical field experience at least 6 weeks prior to post-testing.

Finally, arguing from a methodological perspective, using implicit measures in pre-post designs can be criticized, as low test-retest reliability could imply "occasion-specific variance" (Schnabel et al., 2008a, p. 212). These variations might be due to the actual strength of the associations measured or unidentified sources (Schnabel et al., 2008b, p. 517). However, it is reasonable to assume that changing implicit attitude can be accomplished by sufficient interventions and remain stable over time (Glock and Kovacs, 2013); thus, it should be further investigated as a psychological aspect with respect to inclusion in preservice teachers, even though no significant changes were identified within the current sample.

The non-findings for self-efficacy changes contrast with previous research in teachers (Scanlon and Barnes-Holmes, 2013) as well as preservice teachers. For both groups, significant increases, using however a different self-efficacy questionnaire (Tournaki and Samuels, 2016), were found. Even though reliability scores were not reported in those studies, it is reasonable to assume that the questionable reliability score within the current sample is the main reason for not finding effects on self-efficacy. This argument can be supported as selfconcept, assessed within the stress perception questionnaire, and is conceptually closely related to self-efficacy and the expected changes were present.

\section{Limitations and Future Research}

The current study has several limitations that need to be addressed before drawing a conclusion. The intervention seminars were all executed at the same university in Germany. Thus, generalizability to other countries with potentially different teacher education programs is difficult, especially because attitudes toward inclusion have been shown to be connected to the cultural-historical context (Engelbrecht and Savolainen, 2018). In the same vein, the focus was on PE preservice teachers. Even though, theoretical approaches can easily be adapted to other study majors, the intervention, especially the practical field experience might differ and thus, effects should not be generalized to other study majors. On a methodological level, future research could use specific questionnaires that target attitudes (see Attitudes toward Inclusion in PE by Rischke et al., 2017) or self-efficacy in relation to the study major. PE differs from other school subjects, especially in some organizational aspects (e.g., the lack of student seating, the extended space in a gym, the possibility of injuries), so that teaching inclusively in PE might require different competencies than other school subjects. Thus, the used items, for example for self-efficacy, should be focused on the PE context. Furthermore, as a random assignment of participants to the experimental groups was not feasible because of ethical and practical reasons, causal conclusions cannot be drawn. Also, the sample size in our study is relatively small, although comparable to previous research (e.g., Hodge et al., 2002; Gürsel, 2007; Forlin and Chambers, 2011; Killoran et al., 2014). Nevertheless, we would like to suggest viewing this study as a pilot study, with the main added value of implementing a control group in a field study. The reported effects sizes on significant (e.g., large effect between IG1 and IG2 for explicit attitudes and stress) and also non-significant effects (e.g., medium effect between CG and IG1 for attitudes and stress) are promising for future research to replicate the study with larger sample sizes.

Overall, future research focusing on changing psychological perspectives toward inclusion in preservice teachers should first and foremost provide all the necessary information to allow for a better comparison between studies (in accordance with Lautenbach and Heyder, 2019). In detail, future research should increase their focus on the theoretical underpinning of interventions, while reporting the intervention content in as detailed a manner as possible. This seems particularly important, as it has been shown that interventions informed by theory have a stronger impact for example on reducing prejudice and enhancing inclusion in early childhood (e.g., Aboud et al., 2012, p. 333). On a methodological level, future research needs to continue to implement control groups. Even though a random assignment to groups is often not possible in a university context, quasi-experimental designs that include relevant variables are worthwhile. Additionally, future research should seek to calculate sample size prior to intervention and continue to report power of results. Finally, it could be speculated that other factors might be relevant for the success of an intervention. For example, the length (30 h in 2 vs. 15 weeks in Shade and Stewart, 2001), the quality (e.g., observation and interaction vs. group activity; Hodge et al., 2002) or the intensity of the intervention (e.g., 8 consecutive days vs. 12 concurrent weeks; Killoran et al., 2014) could be worth further investigations. Also, most studies have not yet examined long-term effects on the dependent variables for example via follow-up measurements (e.g., Burton and Pace, 2009). Lastly, another relevant factor that has, to our knowledge, received no attention so far, is the role of and potentially the attitude toward the topic of the lecturer or seminar instructor, which might also be partially determine the success of an intervention. These potential moderating or even mediating factors could be of interest for future research, however, first a solid amount of empirical evidence using theoretical underpinning and strong designs is necessary.

\section{CONCLUSION}

Overall, strictly speaking both interventions did not show statistically significant changes in psychological constructs in comparison to the control group. However, it should be noted that the results on a descriptive level advocate further research and a more detailed investigation of interventions on psychological perspectives in preservice teachers. In this, sample size should be increased, and the type of intervention must be carefully chosen. Only then can practical implications be drawn confidently.

\section{DATA AVAILABILITY STATEMENT}

The datasets generated for this study are available on request to the corresponding author. 


\section{ETHICS STATEMENT}

The studies involving human participants were reviewed and approved by the Ethics Committee of Faculties 12-16 of the TU Dortmund University (Head of Ethics Committee: Prof. Dr. Thomas Jaintner Otto-Hahn-Str. 344227 Dortmund). The patients/participants provided their written informed consent to participate in this study.

\section{AUTHOR CONTRIBUTIONS}

FL conceptualized the design, was responsible for data management and analysis, wrote the original draft including visualizing tables and figures, continued editing, and finalized the manuscript. AM and JK contributed greatly to the intervention content, contributed to manuscript revisions, and provided critical feedback. AH revised the manuscript and gave valuable feedback. EG-S supervised, contributed to the manuscript, and provided critical feedback.

\section{FUNDING}

The current research was part of the project Dortmund Profile for Inclusion-Oriented Learning and Teacher Training (DoProfiL). DoProfiL is part of the "Qualitätsoffensive Lehrerbildung," a

\section{REFERENCES}

Aboud, F. E., Tredoux, C., Tropp, L. R., Brown, C. S., Niens, U., and Noor, N. M. (2012). Interventions to reduce prejudice and enhance inclusion and respect for ethnic differences in early childhood: a systematic review. Dev. Rev. 32, 307-336. doi: 10.1016/j.dr.2012.05.001

Ajzen, I. (1991). The theory of planned behavior. Organ. Behav. Hum. Dec. Process. 50, 179-211. doi: 10.1016/0749-5978(91)90020-T

Allport, F. H. (1954). The structuring of events: outline of a general theory with applications to psychology. Psychol. Rev. 61, 281-303. doi: 10.1037/h0062678

Arthur-Kelly, M., Sutherland, D., Lyons, G., Macfarlane, S., and Foreman, P. (2013). Reflections on enhancing pre-service teacher education programmes to support inclusion: perspectives from New Zealand and Australia. Eur. J. Spec. Needs. Edu. 28, 217-233. doi: 10.1080/08856257.2013. 778113

Avramidis, E., and Norwich, B. (2002). Teachers' attitudes towards integration/inclusion: a review of the literature. Eur. J. Spec. Edu. 17, 129-147. doi: 10.1080/08856250210129056

Bandura, A. (1977). Self-efficacy: toward a unifying theory of behavioral change. Psychol. Rev. 84, 191-215. doi: 10.1037/0033-295X.84.2.191

Bandura, A. (1982). Self-efficacy mechanism in human agency. Am. Psychol. 37, 122-147. doi: 10.1037/0003-066X.37.2.122

Booth, T., and Ainscow, M. (2011). Index for Inclusion: Developing Learning and Participation in Schools. 3rd Revised Version. Available online at: http://www. csie.org.uk/resources/inclusion-index-explained.shtml (October 21, 2019).

Boujut, E., Dean, A., Grouselle, A., and Cappe, E. (2016). Comparative study of teachers in regular schools and teachers in specialized schools in France, working with students with an autism spectrum disorder: stress, social support, coping strategies and burnout. J. Autism Dev. Disord. 46, 2874-2889. doi: 10. 1007/s10803-016-2833-2

Burton, D., and Pace, D. (2009). Preparing pre-service teachers to teach mathematics in inclusive classrooms: a three-year case study. Sch. Sci. Math. 109, 108-115. doi: 10.1111/j.1949-8594.2009.tb17943.x joint initiative of the Federal Government and the Länder, which aims to improve the quality of teacher training. The program was funded by the Federal Ministry of Education and Research (\#01JA1630). The authors are responsible for the content of this publication. We finally acknowledge financial support by Deutsche Forschungsgemeinschaft and TU Dortmund University within the funding program Open Access Publishing.

\section{ACKNOWLEDGMENTS}

We would like to thank the students who took the classes and participated in the study. Also, we want to thank Jana Bergmann for her support during data collection and preparation. We would like to very much thank the rehab and disabled sports community Dortmund $51 \mathrm{e} . \mathrm{V}$. for opening their doors to us. Finally, we thank the Academic Lab (Language Clinic, Leipzig University) for their professional support.

\section{SUPPLEMENTARY MATERIAL}

The Supplementary Material for this article can be found online at: https://www.frontiersin.org/articles/10.3389/feduc. 2020.00007/full\#supplementary-material

Coates, J., and Vickerman, P. (2008). Let the children have their say: children with special educational needs and their experiences of physical educationA review. Support Learn. 23, 168-175. doi: 10.1111/j.1467-9604.2008. 00390.x

Darling-Hammond, L., and Bransford, J.. (2007). Preparing Teachers for a Changing World: What Teachers Should Learn and be Able to do. San Francisco, CA: John Wiley \& Sons.

De Boer, A., Pijl, S. J., and Minnaert, A. (2011). Regular primary schoolteachers' attitudes towards inclusive education: a review of the literature. Int. J. Inclus. Edu. 15, 331-353. doi: 10.1080/136031109030 30089

Desombre, C., Lamotte, M., and Jury, M. (2018). French teachers' general attitude toward inclusion: the indirect effect of teacher efficacy. J. Educ. Psychol. 39, 38-50. doi: 10.1080/01443410.2018.14 72219

Engelbrecht, P., and Savolainen, H. (2018). A mixed-methods approach to developing an understanding of teachers' attitudes and their enactment of inclusive education. Eur. J. Spec. Needs Edu. 33, 660-676. doi: 10.1080/ 08856257.2017.1410327

Field, A. (2013). Discovering Statistics Using IBM SPSS Statistics. London: Sage Publications.

Forlin, C., and Chambers, D. (2011). Teacher preparation for inclusive education: Increasing knowledge but raising concerns. Asia Pac. J. Teach. Edu. 39, 17-32. doi: 10.1080/1359866X.2010.540850

Gaab, J. (2009). PASA-Primary appraisal secondary appraisal. Verhaltenstherapie 19, 114-115. doi: 10.1159/000223610

Gawronski, B., and Bodenhausen, G. V. (2006). Associative and propositional processes in evaluation: an integrative review of implicit and explicit attitude change. Psychol. Bull. 132, 692-731. doi: 10.1037/0033-2909.132. 5.692

Glock, S., and Kovacs, C. (2013). Educational psychology: using insights from implicit attitude measures. Educ. Psychol. Rev. 25, 503-522. doi: 10.1007/ s10648-013-9241-3 
Gürsel, F. (2007). Attitudes of physical education majors in Turkey towards disability are changed by adaptive physical education training. Percept. Motor. Skill. 104, 166-170. doi: 10.2466/pms.104.1

Heyder, A., Südkamp, A., and Steinmayr, R. (2020). How are teachers' attitudes toward inclusion related to the social-emotional school experiences of students with and without special educational needs? Learn. Individ. Differ. 77. doi: 10.1016/j.lindif.2019.101776

Hodge, S. R., Davis, R., Woodard, R., and Sherrill, C. (2002). Comparison of practicum types in changing preservice teachers' attitudes and perceived competence. Adapt. Phys. Act. Q. 19, 155-171. doi: 10.1123/apaq.19.2.155

Hutzler, Y., Zach, S., and Gafni, O. (2005). Physical education students' attitudes and self-efficacy towards the participation of children with special needs in regular classes. Eur. J. Spec. Needs. Edu. 20, 309-327. doi: 10.1080/ 08856250500156038

Kawakami, K., Dovidio, J. F., Moll, J., Hermsen, S., and Russin, A. (2000). Just say no (to stereotyping): effects of training in the negation of stereotypic associations on stereotype activation. J. Pers. Soc. Psychol. 78, 871-888. doi: 10.1037/0022-3514.78.5.871

Killoran, I., Woronko, D., and Zaretsky, H. (2014). Exploring preservice teachers' attitudes towards inclusion. Int. J. Inclus. Edu. 18, 427-442. doi: 10.1080/ 13603116.2013 .784367

Krischler, M., and Pit-ten Cate, I. M. (2019). Pre- and in-service teachers' attitudes toward students with learning difficulties and challenging behavior. Front. Psychol. 10:327. doi: 10.3389/fpsyg.2019. 00327

Kurniawati, F., De Boer, A. A., Minnaert, A. E. M. G., and Mangunsong, F. (2014). Characteristics of primary teacher training programmes on inclusion: a literature focus. J. Educ. Res. 56, 310-326. doi: 10.1080/00131881.2014. 934555

Lautenbach, F. (2019). The main predictor of preservice physical education teachers' attitude toward inclusion is stress appraisal. Int. J. Phys. Educ. LVI, $11-20$.

Lautenbach, F., and Antoniewicz, F. (2018). Ambivalent implicit attitudes towards inclusion in preservice PE teachers: the need for assessing both implicit and explicit attitudes towards inclusion. Teach. Teach. Educ. 72, 24-32. doi: 10.1016/ j.tate.2018.01.003

Lautenbach, F., and Heyder, A. (2019). Changing attitudes to inclusion in preservice teacher education: a systematic review. J. Educ. Res. 61, 251-253. doi: 10.1080/00131881.2019.1596035

Lazarus, R. S. (2000). How emotions influence performance in competitive sports. Sport. Psychol. 14, 229-252. doi: 10.1123/tsp.14.3.229

Leineweber, H., Meier, S., and Ruin, S. (2015). Alle inklusive?!: subjektive theorien von sportlehrkräften zu inklusion. ['All inclusive?!: PE teachers' subjective theories on inclusion']. Sportunterricht 64, 9-14.

Lüke, T., and Grosche, M. (2017). Implicitly measuring attitudes towards inclusive education: a new attitude test based on single-target implicit associations. Eur. J. Spec. Needs Edu. 33, 424-436. doi: 10.1080/08856257.2017.1 334432

McHatton, P. A., and Parker, A. (2013). Purposeful preparation: longitudinally exploring inclusion attitudes of general and special education pre-service teachers. Teach. Educ. Spec. Educ. 36, 186-203. doi: 10.1177/08884064134 91611

Meijer, C. J. W. (2011). Vorwort (Inklusionsorientierte Lehrerbildung in Europa. Chancen und Herausforderungen) [Preface Inclusion-Oriented Teacher Education in Europe. Chances and Challenges.]. Available online at: https://www.kmk-pad.org/fileadmin/Dateien/download/ VERANSTALTUNGSDOKU/Inklusion2012/TE4I-Bericht.pdf (March 16, 2017).

O’Brien, D., Kudláček, M., and Howe, P. D. (2009). A contemporary review of English language literature on inclusion of students with disabilities in physical education: a European perspective. Eur. J. Adapt. Phys. Act. 2, 46-61. doi: 10.5507/euj.2009.004

Pajares, F. M. (1992). Teachers' beliefs and educational research: cleaning up a messy construct. Rev. Educ. Res. 62, 307-332. doi: 10.3102/00346543062003307

Perfecto, H., Galak, J., Simmons, J. P., and Nelson, L. D. (2017). Rejecting a bad option feels like choosing a good one. J. Pers. Soc. Psychol. 113, 659-670. doi: $10.1037 /$ pspa0000092
Pettigrew, T. F., and Tropp, L. R. (2005). "Allport's intergroup contact hypothesis: its history and influence," in On the Nature of Prejudice: Fifty Years After Allport, eds J. F. Dovidio, P. Glick, and L. P. Rudman (Oxford: Blackwell), 262-277. doi: 10.1002/9780470773963.ch16

Qi, J., and Ha, A. S. (2012). Inclusion in physical education: a review of literature. Int. J. Disabil. Dev. Educ. 59, 257-281. doi: 10.1080/1034912x.2012.697737

Reuker, S., Rischke, A., Kämpfe, A., Schmitz, B., Teubert, H., Thissen, A., et al. (2016). Inklusion im sportunterricht. Ein überblick über internationale forschungsergebnisse aus den Jahren 2005 bis 2014. [Inclusion in physical education. An overview of international research results from 2005 to 2014]. Ger. J. Exerc. Sport Res. 46, 88-101. doi: 10.1007/s12662-0160402-7

Rischke, A., Heim, C., and Gröben, B. (2017). Nur eine Frage der Haltung? Eine empirische analyse von personen- und institutionenbezogenen einflussgrößen auf die einstellungen von sportlehrkräften der sekundarstufe I zur schulischen Inklusion. [Just a question of attitude? An empirical analyses of personal and institutional factors impacting attitude towards inclusion in PE teachers for primary schools.]. Ger. J. Exerc. Sport Res. 47, 149-160. doi: 10.1007/s12662017-0437-4

Ryan, R. M., and Deci, E. L. (2000). Self-determination theory and the facilitation of intrinsic motivation, social development, and well-being. Am. Psychol. 55, 68-78. doi: $10.1037 / 0003-066 x .55 .1 .68$

Scanlon, G., and Barnes-Holmes, Y. (2013). Changing attitudes: supporting teachers in effectively including students with emotional and behavioural difficulties in mainstream education. J. Emot. Behav. Diff. 18, 374-395. doi: 10.1080/13632752.2013.769710

Schnabel, K., Asendorpf, J. B., and Greenwald, A. G. (2008a). Assessment of individual differences in implicit cognition: a review of IAT measures. Eur. J. Psychol. Assess. 24, 210-217. doi: 10.1027/1015-5759.24. 4.210

Schnabel, K., Asendorpf, J. B., and Greenwald, A. G. (2008b). "Using implicit association tests for the assessment of implicit personality self-concept," in The SAGE Handbook of Personality Theory and Assessment, eds G. J. Boyle, G. Matthews, and D. H. Saklofske (Thousand Oaks, CA: Sage Publications), 508-528. doi: 10.4135/9781849200479.n24

Schön, D. A. (2017). The Reflective Practitioner: How Professionals Think in Action. London: Routledge.

Schwab, S., and Seifert, S. (2015). Einstellungen von Lehramtsstudierenden und pädagogikstudierenden zur schulischen Inklusion-ergebnisse einer quantitativen untersuchung. [Attitudes towards inclusion in preservice teachers and students of pedagogy-results of a quantitative investigation.]. Z. Bildforsch. 5, 73-84. doi: 10.1007/s35834-0140107-7

Schwarzer, R., and Hallum, S. (2008). Perceived teacher self-efficacy as a predictor of job stress and burnout: mediation analyses. J. Appl. Psychol. 57, 152-171. doi: 10.1111/j.1464-0597.2008.00359.x

Seifried, S., and Heyl, V. (2016). Konstruktion und validierung eines einstellungsfragebogens zu Inklusion für Lehrkräfte (EFI-L) [“Construction and validation of a questionnaire on attitudes towards inclusion for teachers"]. Empirische Sonderpädagogik 1, 22-35.

Shade, R. A., and Stewart, R. (2001). General Education and Special Education Preservice Teachers' Attitudes Toward Inclusion. Prev. Sch. Fail. 46, 37-41. doi: 10.1080/10459880109603342

Shadish, W. R., Cook, T. D., and Campbell, D. T. (2001). Experimental and Quasi-Experimental Designs for Generalized Causal Inference. Belmont, CA: Wadsworth Cengage Learning.

Sherrill, C. (2004). Adapted Physical Activity, Recreation, and Sport: Crossdisciplinary and Lifespan. Boston: McGraw-Hill Higher Education.

Tournaki, N., and Samuels, W. E. (2016). Do graduate teacher education programs change teachers' attitudes toward inclusion and efficacy beliefs? Action Teach. Educ. 38, 384-398. doi: 10.1080/01626620.2016.12 26200

United Nations, (2006). Convention on the Rights of Persons with Disabilities. Available online at: https://www.un.org/disabilities/documents/convention/ convoptprot-e.pdf (October 21, 2019).

Wanzek, J., Swanson, E., Vaughn, S., Roberts, G., and Fall, A. M. (2016). English learner and non-English learner students with disabilities: content 
acquisition and comprehension. Except. Children 82, 428-442. doi: 10.1177/ 0014402915619419

Wegner, M. (2001). Sport und Behinderung. [Sport and Disability.]. Schorndorf: Verlag Karl Hofmann.

Yellin, P. G., Yellin, D., Claypool, P. L., Mokhtari, K., Carr, R., Latiker, T., et al. (2003). I'm not sure I can handle the kids, especially, the, uh, you know special ed kids. Action Teach. Educ. 25, 14-19. doi: 10.1080/01626620.2003.104 63288

Yeo, L. S., Chong, W. H., Neihart, M. F., and Huan, V. S. (2014). Teachers' experience with inclusive education in Singapore. Asia Pac. J. Teach. Edu. 36, 69-83. doi: 10.1080/02188791.2014.934781
Conflict of Interest: The authors declare that the research was conducted in the absence of any commercial or financial relationships that could be construed as a potential conflict of interest.

Copyright (c) 2020 Lautenbach, Korte, Möhwald, Heyder and GrimmingerSeidensticker. This is an open-access article distributed under the terms of the Creative Commons Attribution License (CC BY). The use, distribution or reproduction in other forums is permitted, provided the original author(s) and the copyright owner(s) are credited and that the original publication in this journal is cited, in accordance with accepted academic practice. No use, distribution or reproduction is permitted which does not comply with these terms. 